\title{
Effect of Statins on Endothelial Progenitor Cell (EPC) Migration from Peripheral Blood of Stable Coronary Artery Disease Patient
}

\author{
Tyagita Verdena Rani Savitri, Yudi Her Oktaviono, Djoko Soemantri
}

\begin{abstract}
Background: Endothelial progenitor cell (EPC) participates in endothelial repair and new blood vessel growth. Cardiovascular pharmacotherapy has been shown to improve the amount and function of EPC in patients with cardiovascular risk. Many studies report that statins have a beneficial effect on EPC by increasing the number and function of EPC, including the migration function. Therefore, we conducted a study to analyze the effects of three different statins on EPC migration. Our aim is to analyze the effect of statins on EPC migration from peripheral blood of stable coronary artery disease (SCAD) patient.

Methods: This was an in vitro true experimental post-test only control group design. The MNCs were isolated from peripheral blood of SCAD patient and were cultured in Stemline II Hematopoietic Stemcell Expansion Medium in 3 days. Then samples were put into four groups, simvastatin $0.5 \mu \mathrm{mol} / \mathrm{L}$, atorvastatin $0.5 \mu \mathrm{mol} / \mathrm{L}$, rosuvastatin $0.5 \mu \mathrm{mol} / \mathrm{L}$ and control, then incubated for 48 hours. Immunocytochemical examination was performed to evaluate expression of CD $34^{+}$. On the 5 th day of culture, $5 \times 10^{5}$ cells per group were transferred to the upper chamber of the transwell system, then incubated for I day. Cells that migrated to the lower chamber of transwell system were calculated by automatic cell counter with typhan blue coloring. Data were analyzed by independent T-test and ANOVA.

Results: The results of independent T-tests showed a significant increase in EPC migration in the simvastatin, atorvastatin, and rosuvastatin groups compared with the control group $(234000 \pm 1290.994,265000 \pm 1290.994,203000 \pm 1290.994$ vs I7407I.43 $\pm 1426785, \mathrm{p}<0.05)$. EPC migration also differed between statin groups, where the highest effect was found in the atorvastatin group. EPC migration in the atorvastatin group was higher than the simvastatin group $(265,000 \pm 1290,994$ vs $234,000 \pm 1290,994$, $p$ $<0.05)$, and simvastatin was higher than the rosuvastatin $(234,000 \pm 1290,994$ vs $203000 \pm 1290$. 994, p < 0.05). Immunocytochemical examination showed a positive expression on CD34+.

Conclusion: Statins increase EPC migration from peripheral blood of SCAD patient. Atorvastatin showed the highest EPC migration, followed by simvastatin, and rosuvastatin.
\end{abstract}

(Indonesian J Cardiol. 2019;40:202-205)

Keywords: EPC migration, simvastatin, atorvastatin, rosuvastatin

Department of Cardiology and Vascular Medicine, Faculty of Medicine, Universitas Airlangga, Dr. Soetomo Hospital, Surabaya, Indonesia

\section{Correspondence:}

dr. Tyagita Verdena Rani Savitri

Departemen Kardiologi dan Kedokteran Vaskular

Fakultas Kedokteran Universitas Airlangga,

RSUD Dr. Soetomo Surabaya, Indonesia.

E-mail: tyagita_rani@yahoo.com

\section{Introduction}

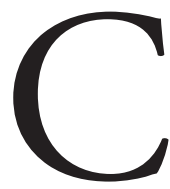

oronary heart disease is a major cause of morbidity and mortality worldwide. Improvements in the quality of therapy for this disease were not accompanied by a significant reduction in recurrence rates. The discovery that cells originating from the bone marrow known as endothelial progenitor cells (EPC) play a role in 
endothelial cell repair and new vascular growth has changed the model of the pathogenesis of cardiovascular disease1. EPC is part of a single nucleated cell or mononuclear cell (MNC) that has several hematopoetic stem cell markers, namely CD34 and CD133. Some physiologica ${ }^{1}$ stimuli, ischaemic response, and some drugs have been known affecting the number and function of $\mathrm{EPC}^{2}$. Statins or HMG-CoA reductase inhibitors reduce cholesterol levels through inhibition of HMG-CoA reductase. Some studies report statins to have beneficial effects on EPC by increasing EPC proliferation and migration through activation of the endothelial nitric oxide synthase (eNOS) pathway ${ }^{3}$. In a previous study, it was found that simvastatin, atorvastatin, and rosuvastatin provided an increase of EPC proliferation in peripheral blood of SCAD patients when compared with controls, where atorvastatin showed the most significant proliferation result ${ }^{4}$.

\section{Methods}

Blood samples were taken from patients with SCAD which were men, 40-59 years old, had narrowing of $\geq 50 \%$ in the left main coronary artery and $\geq 70 \%$ in one or several of the major coronary arteries from angiography.

Patients with history of acute myocardial infarction, acute limb ischemia, stent placement, coronary artery bypass grafting, diabetes mellitus, smoking, and anemia were excluded.

Written informed consent was obtained from patients before peripheral blood drawing. The protocol was approved by local ethics committee (0379/KEPK/ VII/2018).

\section{Isolation and culture of EPCs}

Forty $\mathrm{ml}$ of peripheral blood from SCAD patient was diluted with phosphate buffered saline (PBS) containing $2 \%$ of fetal bovine serum (FBS). It was then centrifuged on Ficoll-Histopaque density gradients and interface mononuclear cells (MNCs) were collected. After two washes in PBS containing $2 \%$ of FBS, pellet were diluted with stemline II hematopoietic stemcell expansion medium, and these cells were counted using hemocytometry. $5 \times 106$ cells $/ \mathrm{ml}$ mononuclear cells were plated on 6-fibronectin coated well plates. After two days, nonadherent cells were transferred into new fibronectin coated well plates and incubated again for 24 hours.

\section{Statin}

After 3 days, EPC culture was divided into 4 groups. Each group was given simvastatin $0.5 \mu \mathrm{mol} / \mathrm{L}$, atorvastatin $0.5 \mu \mathrm{mol} / \mathrm{L}$, rosuvastatin $0.5 \mu \mathrm{mol} / \mathrm{L}$, and control, then cell culture was incubated for next 48 hours

\section{EPC migration assay}

After EPC culture was incubated for 72 hours, $5 \mathrm{x}$ $10^{5}$ cells $/ \mathrm{ml}$ were transferred to the transwell upper chamber. The bottom chamber transwell was given 2 $\mathrm{ml}$ of media. After 24 hours of incubation, the nonmigratory cells on the upper side of upper transwell insert were manually removed using sterile cotton swabs. The upper and lower side of insert system were washed using PBS. Cells on the bottom side of transwell insert system were detached by trypsination method (Figure 1). The new medium was placed on the receiver plate and added $500 \mu \mathrm{l}$ of trypsin + EDTA solution $0.5 \%$, then the insert was returned to the receiver plate and incubated for 10 minutes. The detached cells on the receiver plate were read using a cell counter with tryphan blue coloring to determine the number of migrating cells.

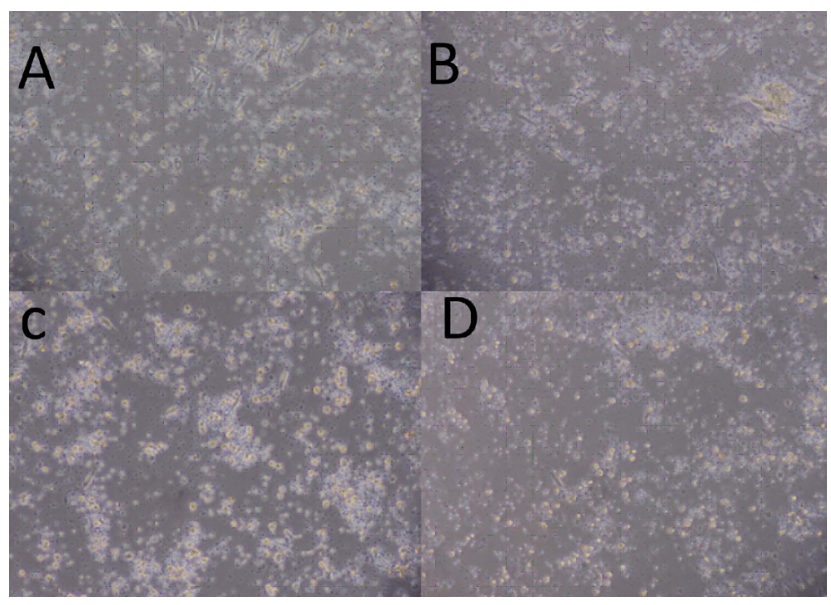

Figure 1. Migrated EPC Cells. A: EPC cells in bottom side of insert transwell of Simvastatin $0.5 \mu \mathrm{mol} / \mathrm{L}$ group, B: EPC cells in bottom side of insert transwell of Atorvastatin $0.5 \mu \mathrm{mol} / \mathrm{L}$ group, C: EPC cells in bottom side of insert transwell of Rosuvastatin $0.5 \mu \mathrm{mol} / \mathrm{L}$ group, D: EPC cells in bottom side of insert transwell of control group 


\section{Immunofluorescence assay}

Cells were washed with PBS and fixed with 3\% formaldehyde for 15 minutes. Cells then added with $1 \%$ serum and washed again with PBS. Cells were stained with a FITC anti-CD34 antibody. Expression of the cells was documented with fluorescence microscope

\section{Statistical analysis}

Data were expressed as mean \pm SD. To analyse differences, one-way ANOVA was used. Differences were considered significant if $\mathrm{p}$-values were $<0.05$. All statistical analyses were performed with SPSS for Windows (IBM Corp., Armonk, NY).

\section{Results}

\section{Statin increases EPC migration}

To investigate the effect of statins on EPC migration, we added three different types of statins on EPC cultures. In this study showed a significant increase of EPC migration in simvastatin, atorvastatin, and rosuvastatin groups compared with control group $(234000 \pm 1290$. 994, $265000 \pm 1290.994,203000 \pm 1290.994$ vs. $174071.43 \pm 1426.785, \mathrm{p}<0.05)$. It also revealed significant difference in EPC migration between each experiment groups, which atorvastatin showed the highest effect. EPC migration in atorvastatin was higher than simvastatin group $(265000 \pm 1290$ vs. $234000 \pm$ 1290. 994, $\mathrm{p}<0.05)$, and simvastatin gruop was also higher than rosuvastatin group $(234000 \pm 1290.994$ vs. $203000 \pm 1290.994, \mathrm{p}<0.05$ ) (Figure 2).

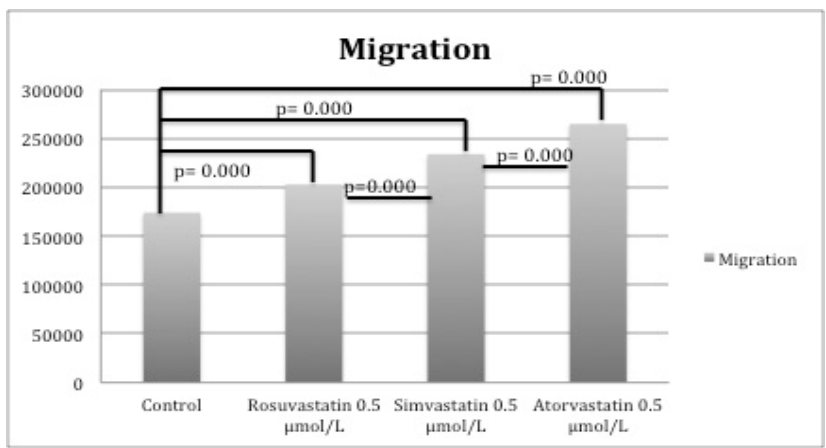

Figure 2. Statins increase EPC migration. EPC migration were expressed as cell $/ \mathrm{ml}$.

\section{Immunofluorescence assay}

CD34 is one of the positive marker for EPC. Before migration assay, one of the well was washed with PBS and stained with a FITC anti-CD34 antibody. Expression of CD34 was green under fluorescence microscope (Figure3).

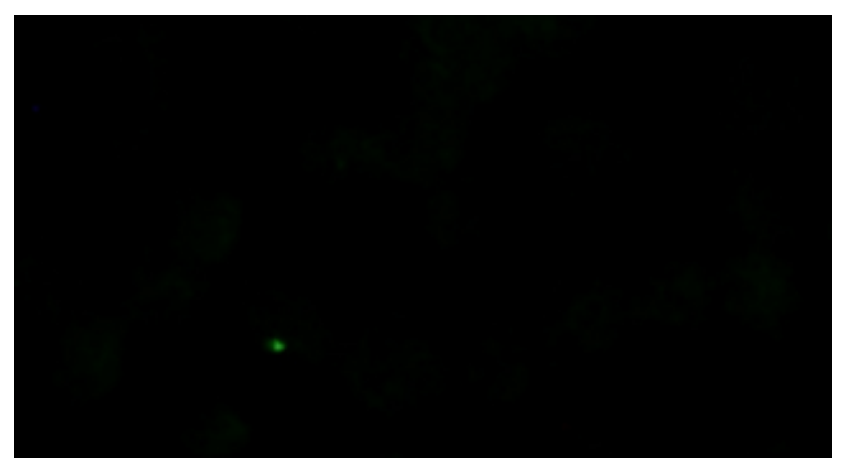

Figure 3. Immunofluorescence expression of CD34

\section{Discussion}

The results of the this study demonstrated that statin significantly increased EPC migration in patients with SCAD. There were different level in EPC migration induced by each statins. Atorvastatin had the highest effect of EPC migration, and simvastatin could promote EPC migration more than rosuvastatin.

Many studies have reported the beneficial effects of statin on EPCs. Similar to this result, Llevadot, et al. reported that simvastatin increased EPC proliferative activity and function of EPC using EPC culture assay of peripheral blood from simvastatin-treated animals in vivo ${ }^{5}$. Spiel, et al. explored the effect of statin using simvastatin and rosuvastatin. The results showed that five days pre-treatment with $80 \mathrm{mg}$ of simvastatin increased CFU 3.5-fold, whereas pre-treatment with $40 \mathrm{mg}$ of rosuvastatin led to a 2.6 fold increase as compared to baseline values ${ }^{6}$. Dimmeler, et al. also used three different types of statins, which were simvastatin, mevastatin, and atorvastatin. The results demonstrated that incubation of isolated human MNCs with statin increased the number of EPCs. Atorvastatin augmented the number and function of EPCs more than simvastatin?

Dimmeler, et al. demonstrated that statins enhanced the mobilization of EPCs from bone marrow to newly forming blood vessels through the PI3K/Akt pathway, which lead to an increase in endothelial nitric oxide 
synthase (eNOS) and nitric oxide (NO) production, as $\mathrm{NO}$ is essential for EPC proliferation ${ }^{7,8}$. The mechanism underlying different effect of statins on EPC migration still needs to be determined. Although all statins share a common mechanism of action, they differ in terms of their chemical structures, pharmacokinetic profiles, and lipid modifying efficacy. These differences might influence the effect on EPC migration induced by different types of statin.

\section{Conclusion}

The results of this study define that statin increases EPC migration from peripheral blood of SCAD patient. Our data suggests that atorvastatin has the highest EPC migration effect, followed by simvastatin, and rosuvastatin.

\section{Acknowledgments}

We would like to thank Clinical Research Unit of Dr. Soetomo Hospital for the grant support, Stem Cell Laboratory Institute of Tropical Disease Airlangga University for laboratory support, and Prof. Ferry Sandra for invaluable support.

\section{Ethical Clearance}

This study was approved by the institution's ethic committee.

\section{Conflict Of Interest}

None

\section{Publication Agreement}

The authors of this article give permission to Indonesian Journal of Cardiology to publish this article if this article is accepted

\section{Funding}

Grant partially provided by Clinical Research Unit, Dr. Soetomo Hospital Surabaya.

\section{List of Abbreviations}

CFU: colony forming unit

eNOS: endothelial nitric oxide synthase

EPC: endothelial progenitor cell

FBS: phosphate buffered saline

HMG-CoA: Hydroxymethyl glutaryl coenzyme A

NO: nitric oxide

PBS: phosphate buffered saline

SCAD: stable coronary artery disease

\section{References}

1. Fadini GP, Agostini C, Sartore S, Avogaro A. Endothelial progenitor cells in the natural history of atherosclerosis. Ath- erosclerosis. 2007;194(1):4654.

2. ShantsilaE, Watson T, Tse HF, Lip GYH. Endothelial colony forming units: Are they a reliable marker of endothelial progeni- tor cell numbers? Annals of Medicine. 2007;39:474-9.

3. Lee PSS, Kian K. Poh. Endothelial progenitor cells in cardio- vascular diseases. World J Stem Cells. 2014;6(3):355-66.

4. Meuthia F., Oktaviono Y. H., Soemantri D. Effects of Statins on Endothelial Progenitor Cell Proliferation from Peripheral Blood of Stable Coronary Artery Disease Patient J Kardiol Indones. 2017;38:6-12

5. Llevadot J, Murasawa S, Kureishi Y, et al. HMGCoA reductase inhibitor mobilizes bone marrowderived endothelial progenitor cells. Journal Clin Invest. 2001;108:399-405.

6. Spiel AO, Mayr FB, Leitner JM, et al. Simvastatin and rosuvas- tatin mobilize endothelial progenitor cells but do not prevent their acute decrease during systemic inflammation. Thrombosis Research. 2008;123:108-113.

7. Dimmeler S, Aicher A, Vasa M, et al. HMG-CoA reductase inhibitors (statins) increase endothelial progenitor cells via the PI 3-kinase/Akt pathway. J Clin Invest. 2001;108:391-7

8. Davignon J. Beneficial cardiovascular pleiotropic effects of statins. Circulation. 2004;109(3):39-43. 